\title{
Ascorbic Acid Distribution in Three Introgression Lines of Tomato
}

Maria Minutolo (Corresponding author)

DISSPAPA, Naples University Federico II

Via Università 100, Portici (NA) 80055, Italy

Tel: 3908-1253-9430 E-mail: minutolm@unina.it

Antonio Di Matteo

DISSPAPA, Naples University Federico II

Via Università 100, Portici (NA) 80055, Italy

Tel: 3908-1253-9208_E-mail: adimatte@unina.it

Carmine Amalfitano

DISSPAPA, Naples University Federico II

Via Università 100, Portici (NA) 80055, Italy

Tel: 3908-1253-9167_E-mail: amalfita@unina.it

Antonio Evidente

DISSPAPA, Naples University Federico II

Via Università 100, Portici (NA) 80055, Italy

Tel: 3908-1253-9178 E-mail: evidente@unina.it

Luigi Monti

DISSPAPA, Naples University Federico II

Via Università 100, Portici (NA) 80055, Italy

Tel: 3908-1253-9027Ｅ-mail: lmonti@unina.it

Angela Errico

DISSPAPA, Naples University Federico II

Via Università 100, Portici (NA) 80055, Italy

Tel: 3908-1253-9430 E-mail: errico@unina.it

This research was supported by grant from Ministero dell'Istruzione, Università e Ricerca (MIUR), Italy, as GenoPOM project: "Laboratorio di genomica per l'innovazione e la valorizzazione della filiera pomodoro".

Contribution from DISSPAPA n. 211

\begin{abstract}
Total ascorbic acid (total-AsA) content and percentage of reduced ascorbic acid (AsA) on total-AsA were investigated and discussed in fruits, leaves, petiole, stem and roots of the Solanum lycopersicum cv M82 and S. pennellii introgression lines IL7-3, IL10-1 and IL12-4. In fruits, total-AsA content showed to be different according to genotype analysed. Higher total-AsA accumulations were observed for IL7-3 and IL12-4 followed by M82 and IL10-1. Total-AsA was generally higher in leaves than in petioles, stems and roots of all genotypes. In roots higher total-AsA concentration and lower AsA percentage was generally observed in introgression lines than M82, in particular for IL7-3.
\end{abstract}

Keywords: Antioxidant, Vitamin C, ILs, Solanum lycopersicum, Solanum pennellii 


\section{Introduction}

In plant, ascorbic acid is a co-factor for many enzymes, contributes to detoxify reactive oxygen species and is important for resistance against biotic and abiotic stress, senescence regulation and floral induction (Arrigoni and De Tullio, 2002, Conklin and Barth, 2004, Barth et al. 2006, El-Gamal et al. 2007, Athar et al. 2008). Ascorbic acid is also implicated in biosynthesis and signalling of many plant hormones, controls stomata function and it is involved in photosynthesis, root development and nutrient uptake (Davey et al. 2000, Bloom et al. 2003, Chen and Gallie 2004, Athar et al. 2008). Ascorbic acid is synthesised through different biosynthetic pathways, mainly Wheeler-Smirnoff pathway that use L-Galactose as key intermediate, and L-Gulose pathway (Wheeler et al. 1998, Wolucka and Van Montagu, 2003). Many genes involved in these pathways have been identified (Conklin et al. 1999, Wolucka et al. 2001, Gatzek et al. 2002, Valpuesta and Botella 2004). In many plant tissues, the concentration of ascorbic acid and its oxidized forms (monohydroascorbate and dehydroascorbate) are tightly controlled and they depend on biosynthesis of ascorbic acid and its recycling by specific reductases.

In human diet the intake of antioxidants, such as ascorbic acid, by the consumption of fruits and vegetables is associated with a reduction of cardiovascular and cancer diseases, as well as other chronic disease (Hung et a1. 2004). The wide complex of antioxidants of such foods exhibits synergistic behaviour for a better therapeutic effect against pro-oxidant and anti-oxidant imbalances (Tiwari 2001). Thus, the selection of crops with high antioxidant concentration is an important goal. Further, the antioxidant recovery from by-products of a crop and processing industry could be of economical benefit for the food and pharmaceutical industries (Knoblich et al. 2005, Pacco et al. 2007).

Among vegetables, tomato (Solanum lycopersicum) is an important source of antioxidants. It is the main vegetable crop in the world (about 126 million tons fresh fruit) next to potato, and in some countries such as USA, fresh and processed tomato consumption shows an increasing trend (FAO Statistical Database, 2008). Tomato is the second source of vitamin $\mathrm{C}$ in human diet after orange and it contains remarkable concentration of other vitamins (folate and E), carotenoids (lycopene and $\beta$-carotene) and polyphenols (Beecher 1998).

Many researches have been conducted to improve antioxidant content in tomato fruit through genetic engineering and breeding schemes (Willits et al. 2005, Butelli et al. 2008, Sapir et al. 2008). Because the breeding schemes often require considerable investments to select and characterize genetic resources, the use of available genetic stocks, such as introgression line populations, is advantageous. Introgression lines (ILs) consist of plants harbouring single homozygous chromosomal segments that are introgressed from a wild parent in the genomic background of the cropped tomato (Eshed and Zamir 1995). ILs have been used for the identification and mapping of QTLs controlling traits of interest (Rousseaux et al. 2005, Schauer et al. 2006) and they represent a valuable tool for understanding the regulation of ascorbic acid (Barone et al. 2009). Tomato libraries have been developed for $S$. pennellii and studies on the primary metabolic traits in populations from interspecific cross with S. lycopersicum are available (Eshed and Zamir 1995, Schauer et al. 2006).

Although many ascorbic acid QTLs have been discovered in IL fruits, very little is known regarding ascorbic acid distribution in the whole plant in relation to fruit QTLs observed. Consequently, in this work the ascorbic acid profile was investigated in several organs collected from selected ILs of S. pennellii in S. lycopersicum cv M82 that, in our experimental condition, differed consistently in fruit ascorbic acid accumulation compared to M82 parental line. Such differences could be useful to evidence factors associated to the introgressions that can affect ascorbic acid distribution.

\section{Materials and Methods}

\subsection{Plant material and morphological analysis}

Three sets of three plants per genotype were grown in greenhouse $\left(24 / 18^{\circ} \mathrm{C}\right.$ day/night $)$, in $5 \mathrm{~L}$ pots filled with a mixture $(1: 1 \mathrm{v} / \mathrm{v})$ of Vesuvian sandy soil and commercial substrate (professional substrate Type-S, FloraGard, Oldenburg, Germany), from November 2007 to flowering or red mature stages. At flowering stage, on one set, plant height, number of main stem nodes, number of the lateral shoots, leaf and leaflet areas, number of roots and their length were evaluated. Also dry weight (DW) was measured after dehydration at $70^{\circ} \mathrm{C}$ for 24 hours. Leaf morphological analysis was performed on two fully expanded leaves collected from node number 5 and 6 . Leaf area was measured by image analyser software ImageJ 1.4 (Rasband 2005). At flowering stage, on a second plant set, ascorbic acid analysis was carried out on stem, petiole, distal and proximal leaflets sampled from two different sections: S1, from node 1 to node 4 , and S2, from node 5 to node 8 (Figure 1). Ascorbic acid was determined also in roots collected and washed by running tap water to remove the soil. Fruits were harvested from the third plant set, grown from November 2007 to red mature stage, and their pericarp was separated. All plant samples were frozen immediately in liquid nitrogen and stored at $-80^{\circ} \mathrm{C}$. 


\subsection{Ascorbic acid extraction and quantification}

Frozen tissue $(250 \mathrm{mg}$ ) was homogenized in a $2 \mathrm{ml}$ plastic tube using a Tissue Liser (Quiagen S.p.A., Milan, Italy) at $4^{\circ} \mathrm{C}$, and ascorbic acid was extracted adding $0,2 \mathrm{ml}$ of $6 \%(\mathrm{v} / \mathrm{v})$ trichloroacetic acid (TCA) (Sigma-Aldrich S.r.l., Milan, Italy) for 10 minutes. After centrifugation (14,000 rpm, $20 \mathrm{~min}$ ), supernatant was collected and diluted to $0.5 \mathrm{ml}$ with TCA. Total ascorbic acid, reduced ascorbic acid plus monodehydroascorbate and dehydroascorbate (total-AsA), and reduced ascorbic acid (AsA) were determined according to Kampfelgen et al. (1995). The analysis were carried out three times

\subsection{Statistical analysis}

Statistical analysis was performed by using the Statistical Package for Social Sciences, version 14 (SPSS Inc Chicago, Illinois). Analysis of variance (ANOVA) was performed on ascorbic acid determination among vegetative tissues and among genotypes for each vegetative tissue and for fruits to evidence differences at $5 \%$ probability level. Student's t-test was applied to determine the differences $(\mathrm{p} \leq 0.05)$ of each morphological measurement between IL7-3 and M82 genotypes. The mean value for each determination and standard error were reported.

\section{Results and Discussion}

A preliminary study was performed on ascorbic acid accumulation in mature fruits of fifty $S$. pennellii introgression lines (ILs). By such investigation, we chose ILs that showed positive and negative differences in comparison to M82 parental line for three years (Di Matteo et al. 2009). The last year (2008) tissues from the whole plant were examined.

The total ascorbic acid (total-AsA), as sum of reduced (AsA) and oxidized forms, in the fruits of IL7-3 and IL12-4 showed to be higher than M82 parental line, while for IL10-1 it was lower than M82 although not statistically significant (Table 1). The increase of total-AsA for IL12-4 and the decrease for IL10-1 were in agreement with other authors (Rousseaux et al. 2005, Schauer et al. 2006); whilst the identification of IL7-3 as the highest total-AsA producer was in contrast to literature where no differences was found in this genotype as compared to M82 (Rousseaux et al. 2005, Schauer et al. 2006, Stevens et al. 2007). However, such result for IL7-3 was confirmed in our laboratory also in previous two years studies (Di Matteo et al. 2009). The discrepancy of ascorbic acid in IL7-3 fruit recorded in our study may arise by the choice of tissue used, which was unpeeled pericarp wall. Rousseaux et al. (2005) and Stevens et al. (2007) analysed entire fresh fruit whereas Schauer et al. (2006) peeled pericarp. However, also the environment highly influences ascorbic acid in fruits so that the genetic effects of single introgression may not be as strong as environmental ones (Toor et al. 2006). Moreover, many observed QTL in field were not always significant in different seasons and they were sometimes not confirmed in greenhouse (Rousseaux et al. 2005, Schauer et al. 2006, Stevens et al. 2007). It has been shown that IL7-3 produces fruits having higher sugar content on wet weight basis than M82 and this was attributed to the overexpression of genes involved in sucrose mobilization (Overy et al. 2005, Baxter et al. 2005). However, for S. pennellii ILs a significant year x genotype interaction has been ascertained for fruit weight and for sugar content on dry weight basis, but not for ascorbic acid (Stevens et al. 2007). Thus, another suggestion for the recorded increased of total-AsA in IL7-3 fruits on fresh weight basis may be a lower water content that unfortunately was not ascertained. Analogously, also the total-AsA increase observed in IL12-4 fruits may arise from lower water content.

The percentages of AsA on total-AsA detected in the fruits was similar among screened genotypes (Table 1) suggesting homogenous ripening level at harvest (Yahia Elhadi et al. 2001, Mondal et al. 2004).

The content of total-AsA was detected through the whole tomato plant and some differences in its distribution in vegetative tissues were found (Figure 2). Among tissues, total-AsA was generally higher in leaves than in petioles, stems and roots for all genotypes. This is because ascorbic acid is mainly produced in mature leaf to be translocated by phloem to non-photosynthetic tissues for its primary role in cell division/growth (Tedone et al. 2004). Such distribution has been shown also in rice and apple leaves compared to stems and roots (Baba and Inada 1956, Zadeh et al. 2007). In general, total-AsA did not change significantly between proximal and distal leaflets of the same leaf except for some differences for M82 and IL12-4. Total-AsA frequently showed lower values in top leaflets as compared with the bottom leaflets, also with some significant differences for IL7-3. This could be related to the full photosynthetic maturity of bottom leaves and/or to a higher transport of ascorbic acid from the top leaves that are closest to the floral sink (Franceschi and Tarlyn 2001). Generally, stem and petiole of all genotypes showed a similar total-AsA content. Furthermore, roots had total-AsA content similar to that of stem except for IL7-3 where it was higher.

Among genotypes, leaflets of each section did not show note worthy differences and petioles and stems evidenced some differences only in section one. IL roots, particularly for IL7-3, showed a higher total-AsA than 
M82. It could be due to a probable higher number of apexes, generally richer in ascorbic acid (Cordoba-Pedregosa et al. 2003), in sampled root of ILs. In fact, IL7-3 roots (Table 2, Figure 3), and less markedly those of IL10-1 and IL12-4 (data not shown), were shorter and more ramified than those of M82. Furthermore, despite the altered root morphology of IL7-3 its root dry weight was similar to that of M82 (Table 2). Such different morphology could be attributed to the reduced vacuolar invertase activity (Sturm 1999, Sergeeva et al. 2006) reported for IL7-3 and IL12-4 (for IL10-1 invertase activity was not ascertained) (Baxter et al. 2005). In fact, in transgenic carrot plants with repressed invertase activity a decrease of plant taproot development has been observed (Tang et al. 1999). A support to this hypothesis was the significant increase of the number of leaves, due to higher lateral shoot development, with lower leaflet area that was recorded in IL7-3 (Table 2, Figure 3). This is in agreement with the higher number of narrower leaves observed in above-mentioned transgenic carrot (Tang et al. 1999). However, IL7-3 leaves showed a total leaf area similar to that of M82 because the presence of more developed intercilary leaflets. In any case, the lower dry weight of IL7-3 leaves (Table 2) was due to their lower thickness by touch. Although IL7-3 showed no increase of node number and lower plant height as compared to M82, both plants showed a similar total dry weight suggesting a similar ability of IL7-3 to fix carbon, which was distributed in higher leaf number due to ramification (Table 2). However, other authors have been observed an increase of weight of IL7-3 vegetative part of plants, on both dry and fresh weight (Eshed and Zamir 1995).

The percentage of AsA on total-AsA was highly variable among tissues and genotypes (Figure 4). About tissues of all genotypes, higher percentage of AsA was frequently observed in stems, petioles and roots than leaves. In stem this was probably because a reducing environment in phloem (Hayashi et al. 2000). The roots of IL genotypes showed lower percentage of AsA than M82. It has been demonstrated that lower percentages of reduced ascorbic acid stimulate root growth and nutrient assimilation (Bloom et al. 2003), further ascorbic acid supplied to roots enhances plant growth under water stress conditions (Athar et al. 2008). Thus the lower percentage of AsA in ILs (Figure 4), and the above-mentioned higher total-AsA (Figure 2), particularly for IL7-3, could be due to plant response to contrast the limiting effect of short root on soil exploration for nutrient and water uptake. Such limiting effect could be less important for IL12-4 and IL10-1 because less evident morphological difference (data not shown) than IL7-3.

A negative effect on plant growth of low invertase expression could be limited by the stimulation of invertase activity. It is known that such stimulation could be related to auxins increase (Mohsin and Naqvi 2007). Hence, the morphological differences observed, as well as ascorbic acid distribution, in the ILs could depend on hormone behaviour such as auxin synthesis/distribution. It has been shown that auxin influences both root morphology and relative content of ascorbic acid in tomato roots (Tyburski et al. 2008). Auxin increasing concentration decreases the percentage of reduced ascorbic acid because it stimulates ascorbate oxidase and ascorbate peroxidase activities and inhibits dehydroascorbate reducing enzymes; concomitantly, auxin reduces root elongation but increases lateral root formation (Tyburski et al. 2008). In fact, an increase in transport of indole acetic acid (IAA) and its accumulation in maize root tips caused an increase of ascorbate oxidase expression and activity, as well as a depletion of the reduced ascorbic acid in quiescent center (mitotically inactive cells within the root meristem) (Kerk et al. 2000). Also radish root segments exposed to exogenous IAA have shown the inhibition of tip growth and the increase of lateral root frequency with local increase in ascorbate oxidase which in turn is responsible for local depletion of reduced ascorbic acid (Kerk et al. 2000). Thus for the IL7-3 an auxin stimulation of lateral root growth could be responsible of the increased total-AsA content with concomitant decrease of AsA percentage. In any case, other hormones could have caused the observed alterations in ILs, for example a decrease of auxin/cytokinin ratio could increase the development of lateral buds (Salisbury et al. 1994) as it was observed in IL7-3.

\section{Conclusion}

The investigated introgression lines IL12-4 and IL10-1 of S. pennellii into S. lycopersicum genome have confirmed the already know higher and lower ascorbic acid accumulation in fruit, respectively, as compared to the cropped M82 genotype, whilst it is the first time that IL7-3 appeared to be an ascorbic acid overproducer. Although the ascorbic acid distribution in vegetative tissues of all investigated genotype was in agreement with that usually expected in herbaceous plants, for IL7-3 the higher total-AsA and the lower percentage of AsA on total-AsA in roots than the other genotypes, and the different morphological traits (shorter and ramified roots, higher number of lateral shoots and thick leaves, than M82) suggested a modification of IL7-3 metabolism. Such modification is probably due to reduced invertase activity and/or different hormones regulation/distribution in IL7-3 plant. This may have also caused the increase of ascorbic acid in its fruit. Again, at our knowledge, no gene involved in ascorbic acid biosynthesis and recycling is reported until now to be introgressed from $S$. 
pennellii in IL7-3 genome as well as in IL10-1 and IL12-4 (Stevens et al. 2007). However, the total-AsA increase observed in IL7-3 fruits may depend by their lower water content that have to be investigated.

Further, yield and quality of crop of all ILs should be ascertained to asses the commercial and health value of fruits. In this context, IL7-3 and IL12-4 seem good candidates because they show better properties in terms of fruit sugar and ascorbic acid contents. In addition for IL7-3 higher resistance to biotic stress, and probably also to water stress, is expected because the ascertained presence of resistance gene I-3 from $S$. pennellii towards Fusarium Oxysporum (Hemming et al. 2004).

\section{Acknowledgment}

The authors sincerely thank Dr Pasquale Chiaiese for comments on earlier drafts of this manuscript.

\section{References}

Arrigoni, O., De Tullio, M. C. (2002). Ascorbic acid: much more than just an antioxidant. Biochimica et Biophysica Acta, 1569, 1-9.

Athar, H. R., Khan, A., Ashraf, M. (2008). Exogenously applied ascorbic acid alleviates salt-induced oxidative stress in wheat. Envirovmental and Experimental Botany, 63, 224-231.

Baba, I., Inada, K. (1956). On the oxidation-reduction potential of tissue fluid of rice plant (in Japanese, with English abstract). Nippon Sakumotsu Gakkai Kiji, 25, 75-77.

Barone, A., Di Matteo, A., Carputo, D., Frusciante, L. (2009). High-throughput genomics enhances tomato breeding efficiency. Current Genomica, 10, 1-9.

Barth, C., De Tullio, M., Conklin, P. L. (2006). The role of ascorbic acid in the control of flowering time and the onset of senescence. Journal of Experimental Botany, 57, 1657-1665.

Baxter, C. J., Sabar, M., Quick, W. P., Sweetlove, L. J. (2005). Comparison of changes in fruit gene expression in tomato introgression lines provides evidence of genome-wide transcriptional changes and reveals links to mapped QTLs and described traits. Journal of Experimental Botany, 56, 1591-1604.

Beecher, G. R. (1998). Nutrient content of tomatoes and tomato products. In Proceeding of the Society for Experimental Biology and Medicine, 218, 98-100.

Bloom, A. J., Meyerhoff, P. A., Taylor, A. R., Rost, T. L. (2003). Root development and absorption of ammonium and nitrate from the rhizosphere. Journal of Plant Growth and Regulation, 21, 416-431.

Butelli, E., Titta, L., Giorgio, M., Mock, H. P., Matros, A., Peterek, S., Schijlen, E. G. W. M., Hall, R. D., Bovy, A. G., Luo, J., Martin, C. (2008). Enrichment of tomato fruit with health-promoting anthocyanins by expression of select transcription factors. Nature Biotechnology, 26, 1301-1308.

Chen, Z, Gallie D. R. (2004). The ascorbic acid redox state controls guard cell signalling and stomatal movement. The Plant Cell, 16, 1143-1162.

Conklin, P. L., Norris, S. R., Wheeler, G. L., Williams, E. H., Smirnoff, N., Last, R. L. (1999). Genetic evidence for the role of GDP-mannose in plant ascorbic acid (vitamin C) biosynthesis. Proceedings of the National Academy of Sciences (PNAS), 96, 4198-4203.

Conklin, P. L., Barth, C. (2004). Ascorbic acid, a familiar small molecule intertwined in the response of plants to ozone, pathogens, and the onset of senescence. Plant, Cell and Environment, 27, 959-971

Cordoba-Pedregosa Mdel, C., Cordoba, F., Villalba, J. M., Gonzales-Reves, J. A. (2003). Differential distribution of ascorbic acid, peroxidase activity, and hydrogen peroxide along the root axis in Allium cepa L. and its possible relationship with cell growth and differentiation. Protoplasma, 221, 57-65.

Davey, M.W., Van Montagu, M., Inze, D., Sanmartin, M., Kanellis, A., Smirnoff, N., Benzie, I. J. J., Strain, J. J., Favell, D., Fletcher, J. (2000). Plant L-ascorbic acid: chemistry, function, metabolism, bioavailability and effects of processing. J Sci Food Agric, 80, 825-860.

Di Matteo, A., Sacco, A., Anacleria, M., Trotta, N., Barone, A. (2009). Identification and transfer of QTLs controlling ascorbic acid content in tomato fruit. Proceedings of the 53rd Italian Society of Agricultural Genetics Annual Congress, Torino, Italy - 16/19 September 2009, ISBN 978-88-900622-9-2, p 1.05

El-Gamal, N. G., Abd-El-Kareem, F., Fotouh, Y. O., El-Mougy, N. S. (2007). Induction of systemic resistance in potato plants against late and early blight diseases using chemical inducers under greenhouse and field conditions research. Research Journal of Agriculture and Biological Sciences, 3, 73-81.

Eshed, Y., Zamir, D. (1995). An introgression line population of Lycopersicon pennellii in the cultivated tomato enables the identification and fine mapping of yield-associated QTL. Genetics, 141, 1147-1162. 
Franceschi, V. R., Tarlyn, N. M. (2001). L-ascorbic acid is accumulated in source leaf phloem and transported to sink tissues in plants. Plant Physiology, 130, 649-656.

Gatzek, S., Wheeler, G. L., Smirnoff, N. (2002). Antisense suppression of L-galactose dehydrogenase in Arabidopsis thaliana provides evidence for its role in ascorbate synthesis and reveals light modulated L-galactose synthesis. The Plant Journal, 30, 541-553.

Hayashi, H., Fukuda, A., Suzui, N., Fujimaki, S. (2000). Proteins in the sieve-element cell complexes: their detection, localization and possible functions. Australian Journal of Plant Physiology, 27, 489-496.

Hemming, M. N., Basuki, S., McGrath, D. J., Carroll, B. J., Jones, D. A. (2004). Fine mapping of the tomato I-3 gene for fusarium wilt resistance and elimination of a co-segregating resistance gene analogue as a candidate for I-3. Theoretical and Applied Genetics, 109, 409-418.

Hung, H. C., Joshipura, K. J., Jiang, R., Hu, F. B., Hunter, D., Smith-Warner, S. A., Colditz, G. A, Rosner, B., Spiegelman, D., Willett, W. C. (2004). Fruit and vegetable intake and risk of major chronic disease. Journal of the National Cancer Institute, 96, 1577-1584.

Kampfenkel, K., Van Montagu, M., Inzé, D. (1995). Effects of Iron excess on Nicotiana plumbagnifolia plants implications to oxidative stress. Plant Physiology, 107, 725-735.

Kerk, N. M., Jiang, K., Feldman, J. L. (2000). Auxin metabolism in the root apical meristem. Plant Physiology, 122, 925-932.

Knoblich, M., Anderson, B., Latshaw, D. (2005). Analyses of tomato peel and seed by-products and their use as a source of carotenoids. Journal of the Science of Food and Agriculture, 85, 1166-1170.

Mohsin, T., Naqvi, F. N. (2007). Auxin-mediated regulation of early growth activities in Vigna radiate: induction and repression of two hydrolases, invertase and $\alpha$-amilase. Journal of Food Agriculture and Environment, 5, 125-127.

Mondal, K., Sharma, N. S., Malhotra, S. P., Dhawan, K., Singh, R. (2004). Antioxidant systems in ripening tomato fruits. Biologia Plantarum, 48, 49-53.

Overy, S. A., Walker, H. J., Malone, S., Howard, T. P., Baxter, C. J., Sweetlove, L. J., Hill, S. A., Quick, W. P. (2005). Application of metabolite profiling to the identification of traits in a population of tomato introgression lines. Journal of Experimental Botany, 56, 287-296.

Pacco, H. C., Cortez, L. A. B., Vigneault, C., Jordan, R. A., Baldassin, R. Jr. (2007). Proposal for producing energy from residues generated during tomato fruit drying process. [Online] Available: http://www.cori.unicamp.br

Rasband, W. S., ImageJ, U. S. (1997-2009). National Institutes of Health, Bethesda, Maryland, USA, http://rsb.info.nih.gov/ij/.

Rousseaux, M. C., Jones, C. M., Adams, D., Chetelat, R., Bennett, A., Powell, A. (2005). QTL analysis of fruit antioxidants in tomato using Lycopersicon pennellii introgression lines. Theoretical and Applied Genetics, 111, 1396-1408.

Salisbury, F. B., Ross, C. W. (1994). in Zanichelli Spa (Eds.), Fisiologia vegetale ( $2^{\text {nd }}$ Italian ed. of $4^{\text {th }}$ American one) (pp. 792). Bologna, Italia, Publisher.

Sapir, M., Oren-Shamir, M., Ovadia, R., Reuveni, M., Evenor, D., Tadmor, Y., Nahon, S., Shlomo, H., Chen, L., Meir, A., Levin, I. (2008). Molecular aspects of Anthocyanin fruit tomato in relation to high pigment. J. Hered. 99, 292-303.

Schauer, N., Semel, Y., Roessner, U., Gur, A., Balbo, I., Carrari, F., Pleban, T., Perez-Melis, A., Bruedigam, C., Kopka, J., Willmitzer, L., Zamir, D., Fernie, A. R. (2006). Comprehensive metabolic profiling and phenotyping of interspecific introgression lines for tomato improvement. Nature Biotechnology, 24, 447-454.

Sergeeva, L. I., Keurentjes, J. J. B., nie Bentsink, L., Vonk, J., van der Plas, L. H. W., Koornneef, M., Vreugdenhil, D. (2006). Vacuolar invertase regulates elongation of Arabidopsis thaliana roots as revealed by QTL and mutant analysis. PNAS, 103, 2994-2999.

Stevens, R., Buret, M., Duffé, P., Garchery, C., Baldet, P., Rothan, C., Causse, M. (2007). Candidate genes and QTLs affecting fruit ascorbic acid content in three tomato populations. Plant Physiology, 143, 1943-1953.

Sturm, A. (1999). Invertases. Primary Structures, Functions, and Roles in Plant Development and Sucrose Partitioning. Plant Physiol. 121, 1-8. 
Tang, G. Q., Lüscher, M., Sturm, A. (1999). Antisense repression of vacuolar and cell wall invertase in transgenic carrot alters early plant development and sucrose partitioning. Plant Cell, 11, 177-190.

Tedone, L., Hancock, R. D., Alberino, S., Haupt, S. (2004). Long-distance transport of L-ascorbic acid in potato. BMC Plant Biology, 4-16.

Tiwari, A. K. (2001). Imbalance in antioxidant defence and human diseases: Multiple approach of natural antioxidants therapy. Current Science, 81, 1179-1187.

Toor, R. K., Savage, G. P., Lister, C. E. (2006). Seasonal variations in the antioxidant composition of greenhouse grown tomatoes. Journal of Food Composition and Analysis, 19, 1-10.

Tyburski, J., Krzemiński, L., Tretyn, A. (2008). Exogenous auxin affects ascorbate metabolism in roots of tomato seedlings. Plant Growth Regulation, 54, 203-215.

Valpuesta, V., Botella, M. A. (2004). Biosynthesis of L-ascorbic acid in plants: new pathways for an old antioxidant. Trends in Plant Science, 9, 573-7.

Wheeler, G. L., Jones, M. A., Smirnoff, N. (1998). The biosynthetic pathway of vitamin C in higher plants. Nature, 393, 365-369.

Willits, M. G., Kramer, C. M., Prata, R. T., De Luca, V., Potter, B. G., Steffens, J. C., Graser, G. (2005). Utilization of the genetic resources of wild species to create a non-transgenic high flavonoid tomato. Journal of Agricultural and Food Chemistry, 53, 1231-1236.

Wolucka, B. A., Persiau, G., Van Doorsselaere, J., Davey, M. W., Demol, H., Vandekerckhove, J., Van Montagu, M., Zabeau, M., Boerjan, W. (2001). Partial purification and identification of GDP-mannose 3",5"-epimerase of Arabidopsis thaliana, a key Jasmonate signalling and ascorbate biosynthesis enzyme of the plant vitamin $\mathrm{C}$ pathway. PNAS, 98, 14843-14848.

Wolucka, B. A., Van Montagu, M. (2003). GDP-mannose 3",5"-epimerase forms GDP-L-gulose, a putative intermediate for the de novo biosynthesis of vitamin $\mathrm{C}$ in plants. Journal of Biological Chemistry, 278, 47483-47490.

Yahia Elhadi, M., Contreras-Padilla, M., Gonzales-Aguilar, G. (2001). Ascorbic acid content in relation to ascorbic acid oxidase activity and polyamine content in tomato and bell pepper fruits during development, maturation and senescence. Lebensm. Wiss. U. Technololy, 34, 452-457.

Zadeh, H., Keulemans, R. J., Davey, M. W. (2007). Expression pattern of key vitamin C biosynthesis genes in apple. Communication in Agricultural and Applied Biological Sciences, Ghent University, 72, 269-273.

Table 1. Total ascorbic acid (tot-AsA), expressed as $\mathrm{mg} / 100 \mathrm{~g}$ of $\mathrm{FW}$, and relative percentage of reduced ascorbic acid (AsA\%) in fruits of S. lycopersicum $v r$ M82 and ILs

\begin{tabular}{ccccc}
\hline Genotype & M82 & IL7-3 & IL10-1 & IL12-4 \\
\hline Tot-AsA & $21.5 \pm 1.5 \mathrm{c}$ & $40.6 \pm 5.7 \mathrm{a}$ & $16.9 \pm 1.3 \mathrm{c}$ & $28.6 \pm 1.4 \mathrm{~b}$ \\
\hline $\mathrm{AsA} \%$ & $77.6 \pm 4.1 \mathrm{a}$ & $87.6 \pm 3.7 \mathrm{a}$ & $77.1 \pm 4.7 \mathrm{a}$ & $81.2 \pm 3.3 \mathrm{a}$ \\
\hline
\end{tabular}

Table 2. Morphological analysis of S. lycopersicum vr M82 and IL7-3 plants

\begin{tabular}{lll}
\hline & M82 & IL7-3 \\
\hline Nodes $(\mathrm{n})$ & $15.0 \pm 1.0 \mathrm{a}$ & $15.0 \pm 0.6 \mathrm{a}$ \\
\hline Lateral shoots $(\mathrm{n})$ & $4.5 \pm 0.4 \mathrm{~b}$ & $8.0 \pm 0.6 \mathrm{a}$ \\
\hline Leaves $(\mathrm{n})$ & $21.0 \pm 1.8 \mathrm{~b}$ & $28.0 \pm 1.1 \mathrm{a}$ \\
\hline Leaflet area $\left(\mathrm{cm}^{2}\right)$ & $40.4 \pm 0.5 \mathrm{a}$ & $23.3 \pm 1.2 \mathrm{~b}$ \\
\hline Leaf area $\left(\mathrm{cm}^{2}\right)$ & $150.7 \pm 13.3 \mathrm{a}$ & $159.6 \pm 22.9 \mathrm{a}$ \\
\hline Leaf DW $(\mathrm{mg})$ & $579.3 \pm 139.0 \mathrm{a}$ & $321.3 \pm 29.2 \mathrm{~b}$ \\
\hline Petiole DW $(\mathrm{mg})$ & $163.4 \pm 32.8 \mathrm{a}$ & $197.7 \pm 6.5 \mathrm{a}$ \\
\hline Roots $(\mathrm{n})$ & $59.0 \pm 15.0 \mathrm{a}$ & $80.0 \pm 11.0 \mathrm{a}$ \\
\hline Root length $(\mathrm{cm})$ & $41.5 \pm 3.9 \mathrm{a}$ & $32.7 \pm 3.2 \mathrm{~b}$ \\
\hline Aerial DW $(\mathrm{g})$ & $7.0 \pm 1.8 \mathrm{a}$ & $6.8 \pm 0.9 \mathrm{a}$ \\
\hline Roots DW $(\mathrm{g})$ & $1.2 \pm 0.2 \mathrm{a}$ & $1.3 \pm 0.1 \mathrm{a}$ \\
\hline
\end{tabular}




\begin{tabular}{lll}
\hline Plant height $(\mathrm{cm})$ & $52.2 \pm 2.2 \mathrm{a}$ & $42.0 \pm 1.1 \mathrm{~b}$ \\
\hline
\end{tabular}

\section{A}
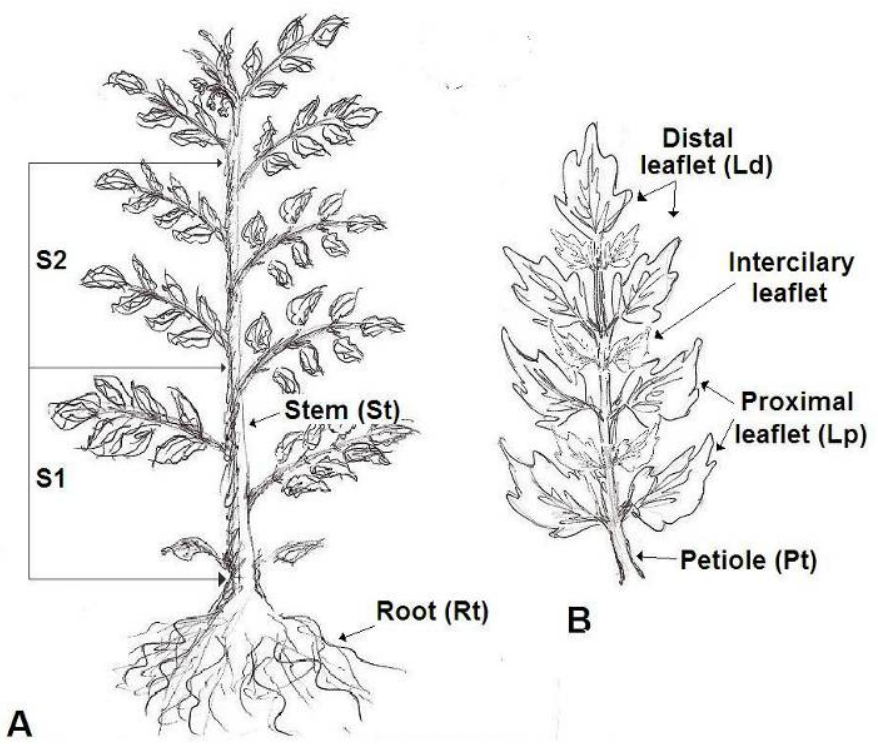

B

Figure 1. Tomato plant (A) and leaf (B). S1 and S2 are the sections from which samples were collected
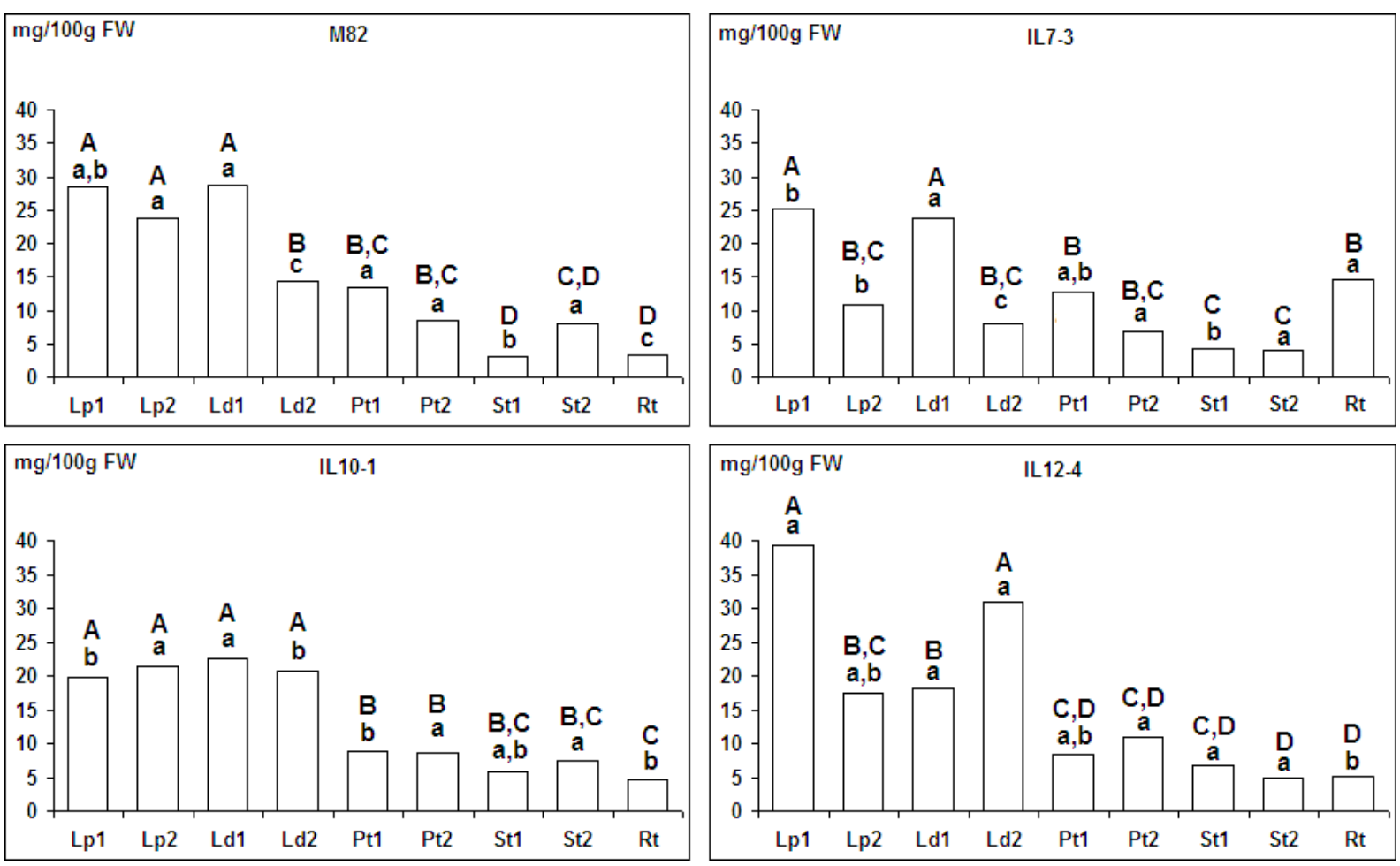

Figure 2. Total ascorbic acid content in leaf, petiole, stem and root of S. lycopersicum vr M82 and ILs, expressed as $\mathrm{mg} / 100 \mathrm{~g}$ of FW. Lp1, Ld1, Pt1 and St1 are proximal leaflets, distal leaflets, petiole and stem from section 1, respectively; Lp2, Ld2, Pt2 and St2 are from section 2, respectively; Rt, roots. Uppercase and lowercase letters represent statistically significant differences ( $\mathrm{p} \leq 0.05)$ among tissues and genotypes, respectively 


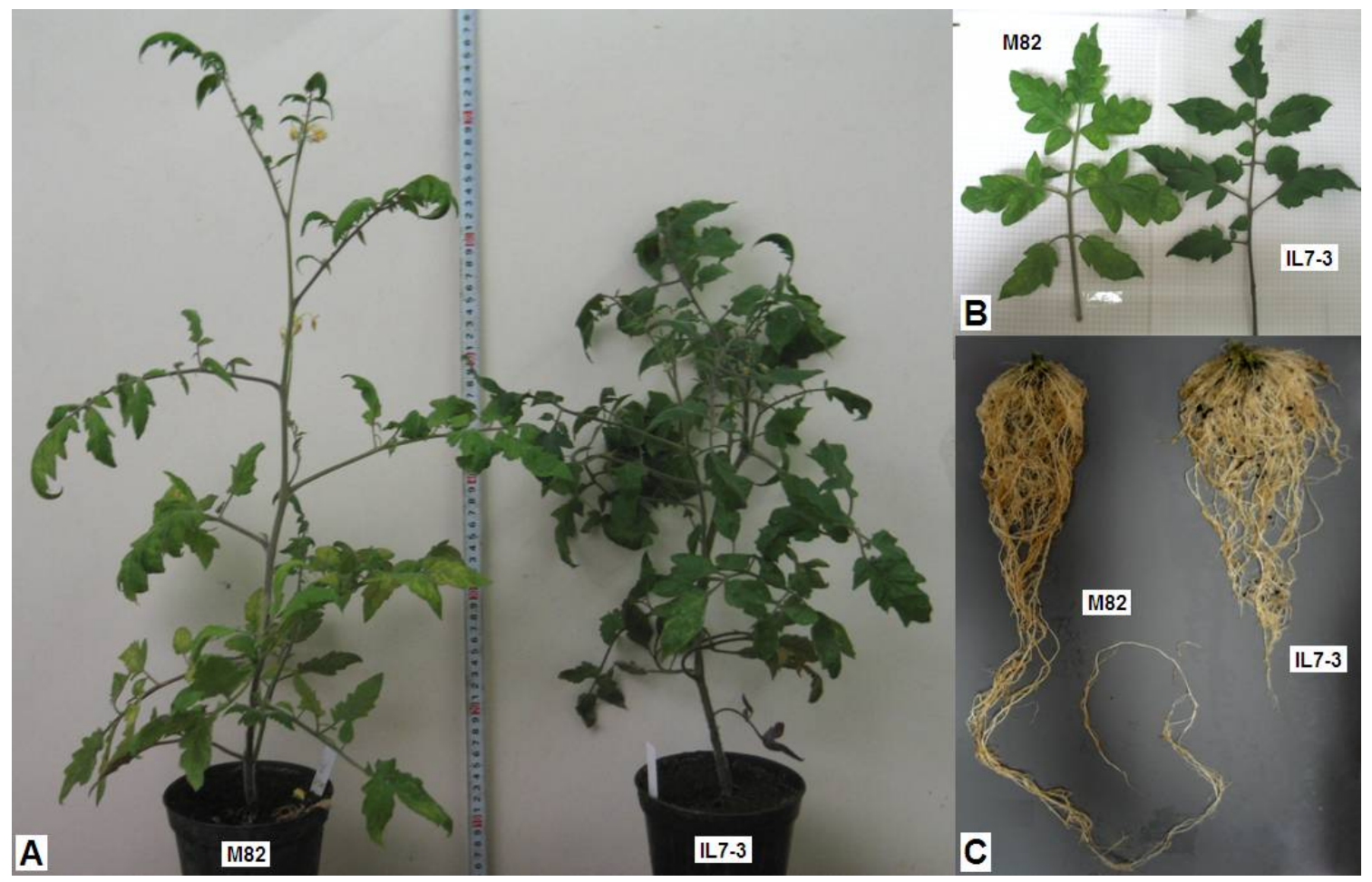

Figure 3. IL7-3 and M82 plants (A), leaves (B) and roots (C)
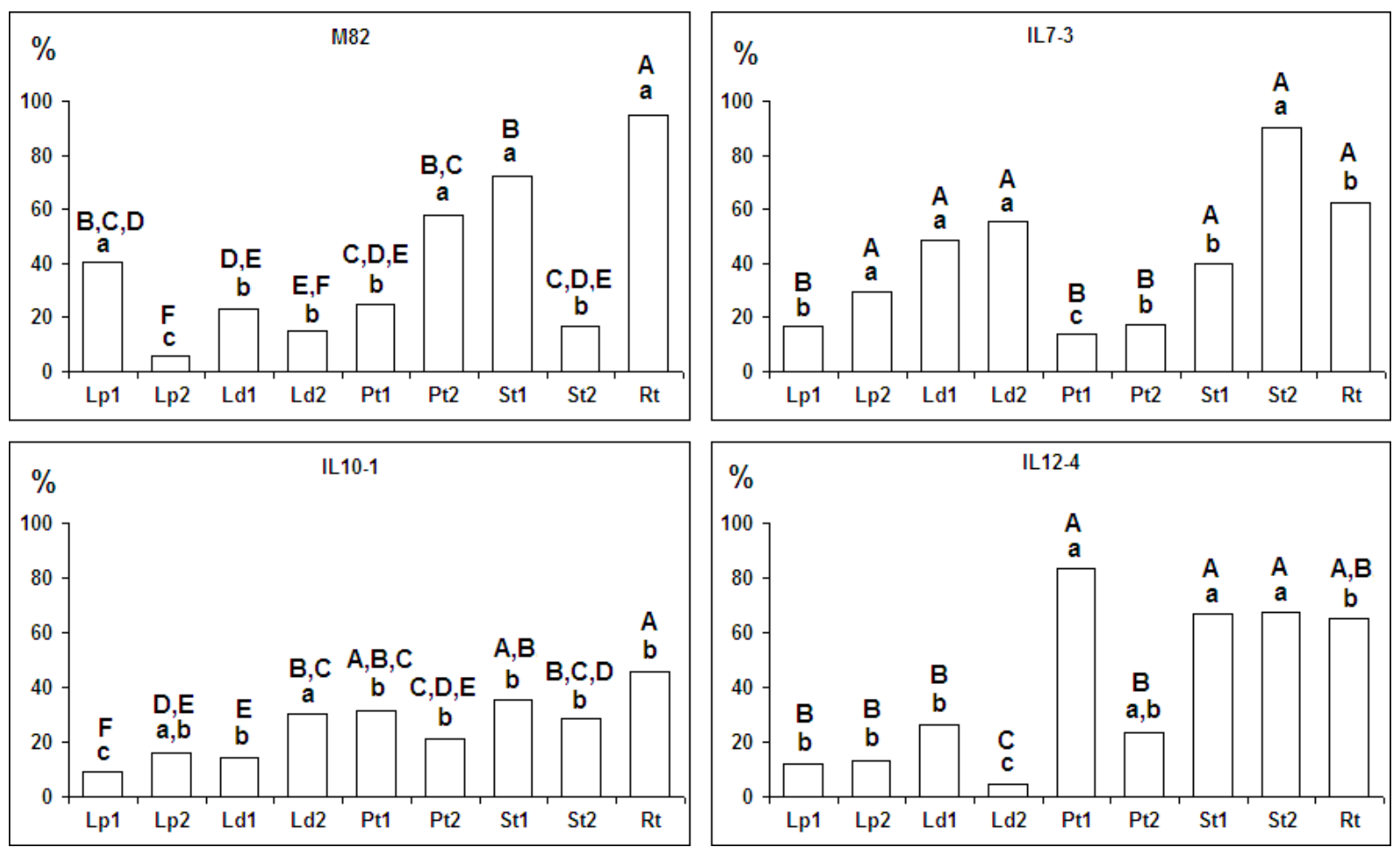

Figure 4. Percentage of AsA on total-AsA in different organs of tomato plants. Uppercase and lowercase letters represent statistically significant differences $(\mathrm{p} \leq 0.05)$ among tissues and genotypes respectively. Lp1, Ld1, Pt1 and St1 are proximal leaflets, distal leaflets, petiole and stem from section 1, respectively; Lp2, Ld2, Pt2 and St2 are from section 2, respectively; Rt, roots 